\title{
Full-temperature covered switching material with triple optic-dielectric states in a lead-free hybrid perovskite
}

Tie Zhang ${ }^{1,2}$, Lulu Chu ${ }^{1}$, Zhixu Zhang ${ }^{1}$, Jie $\mathrm{Li}^{1}$, Wanying Zhang ${ }^{2}$, Pingping Shi ${ }^{1}$, Qiong $\mathrm{Ye}^{1^{*}}$ and $\mathrm{Da}-\mathrm{Wei} \mathrm{Fu}^{1,2^{*}}$

\begin{abstract}
Optic-electric responsive materials have attracted much attention for their applications in temperaturesensing, actuators, and memory switches. However, it is a challenge to integrate various functions to form multifunctional responsive materials. As molecule-based hybrid materials usually consist of organic and inorganic components, the introduction of multiple functions can be achieved through structural construction. Thus far, even though fulltemperature cover is required for device applications, fulltemperature covered multi-switchable hybrid materials have rarely been successfully synthesized. Herein, the dynamic $\left[\left(\mathrm{CH}_{3}\right)_{3} \mathrm{NOH}\right]^{+}$cation and luminous center $\mathrm{Mn}(\mathrm{II})$ were introduced to form a hybrid material $\left[\left(\mathrm{CH}_{3}\right)_{3} \mathrm{NOH}\right]\left[\mathrm{MnCl}_{3}\right]$, showing multiple temperature-responsive behaviors. Upon temperature change, it exhibits multi-state dielectric switching response and intensity or peak shift response of luminous in full-temperature range (low, room, and high temperatures). These responsive behaviors are triggered by the motion or reorientation of $\left[\left(\mathrm{CH}_{3}\right)_{3} \mathrm{NOH}\right]^{+}$cations and inorganic framework. Overall, the switchable photoelectric material has potential applications in multiple encrypted storage and sensor devices.
\end{abstract}

Keywords: responsive material, multiple dielectric states, crystal, perovskite

\section{INTRODUCTION}

Making appropriate changes to adapt to the surrounding environment is essential for all living creatures to sustain life or biological activities. Similar to organisms, some materials can imitate this "behavior" for adapting to ex- ternal stimuli such as temperature, light radiation, pressure, electric and magnetic fields, namely stimuliresponsive materials (SRMs) [1-5]. Usually, by structural change, these materials possess the feature of changing their physical and/or chemical properties under external stimuli, which has aroused considerable attention for sensors, actuators, memory devices, switches, surface engineering, and other intelligent material industries [69]. Thermal SRMs (TSRMs), one group of SRMs, can alter their electric, luminescence, surface, and magnetic properties by thermal stimulation [10-14]. In the past years, extensively studied polymers and inorganic materials have undergone great development $[12,15,16]$. Nevertheless, the difficulty of regulating their structures has hindered their development, especially in the multifunctional material field. Molecular-based hybrid materials, the rising star among this group, have become the focus of TSRMs because of their excellent structural compositions [11,17-19]. Self-assembly of organic and inorganic components is an effective method for synthesis of these hybrid materials. Furthermore, some phasetransition hybrid materials exhibit reversible switchable chemical or physical properties under the external stimuli, which have taken a dominant position in basic research and technical application [20-23].

As is known, for the prospect of inducing bright fluorescence in hybrid halide perovskites, Mn-based hybrid compounds have aroused much attention [24-27]. Recently, Zhang et al. [28,29] revealed two Mn-based $\mathrm{ABX}_{3}$-type perovskites that exhibited ferroelectricity and luminescence properties. Moreover, Bhaskaran et al. [30]

\footnotetext{
${ }^{1}$ Ordered Matter Science Research Center, Jiangsu Key Laboratory for Science and Applications of Molecular Ferroelectrics, Southeast University, Nanjing 211189, China

${ }^{2}$ Institute for Science and Applications of Molecular Ferroelectrics, Key Laboratory of the Ministry of Education for Advanced Catalysis Materials, Zhejiang Normal University, Jinhua 321004, China

* Corresponding authors (emails: dawei@seu.edu.cn (Fu DW); yeqiong@seu.edu.cn (Ye Q))
} 
also studied the optical transmittance and dielectricity of a Mn-based compound systematically. Especially, a two dimensional (2D) $\mathrm{Pb}-\mathrm{Mn}$ heterometallic halide hybrid, $\left(\mathrm{C}_{5} \mathrm{H}_{14} \mathrm{~N}_{2}\right)_{2} \mathrm{~Pb}_{4} \mathrm{MnCl}_{14}$, showed excellent luminescence properties [31]. However, they could not respond to electricity and luminescence simultaneously under temperature stimulation, or achieve multi-segment temperature responses $[20,32]$. Therefore, searching for materials with multiple switchable physical properties and multiple temperature states in the full temperature range remains a challenge.

As a luminous activator, the emission of $\mathrm{Mn}$ (II) complexes originates from the ${ }^{4} \mathrm{~T}_{1 \mathrm{~g}}(\mathrm{G}) \rightarrow{ }^{6} \mathrm{~A}_{\mathrm{lg}}(\mathrm{S})$ transition of $\mathrm{Mn}^{2+}$ ions, which facilitates the preparation of fluorescent hybrid materials. For example, the green luminescence of the tetrahedral manganese halides is produced by $\mathrm{d}$ electron transition configuration from $\left(\mathrm{e}_{\mathrm{g}}\right)^{2}\left(\mathrm{t}_{2 \mathrm{~g}}\right)^{3}$ to $\left(e_{g}\right)^{1}\left(t_{2 g}\right)^{4}$ and the pink luminescence of the octahedral manganese halides is produced by $\mathrm{d}$ electron transition configuration from $\left(\mathrm{t}_{2 \mathrm{~g}}\right)^{3}\left(\mathrm{e}_{\mathrm{g}}\right)^{2}$ to $\left(\mathrm{t}_{2 \mathrm{~g}}\right)^{4}\left(\mathrm{e}_{\mathrm{g}}\right)^{1}$. Therefore, using the self-assembly of a proper organic cation with the manganese halide skeleton is a feasible strategy to design TSRMs with multiple responses and multiple temperature states. Inspired by our previous work on $\left[\left(\mathrm{CH}_{3}\right)_{3} \mathrm{NOH}\right]-\left[\mathrm{CdCl}_{3}\right][33]$ and considering the interaction of $\left(\mathrm{CH}_{3}\right)_{3} \mathrm{NOH}^{+}$cations with the inorganic framework, a novel 1D organic-inorganic hybrid perovskite $\left[\left(\mathrm{CH}_{3}\right)_{3} \mathrm{NOH}\right]\left[\mathrm{MnCl}_{3}\right](\mathbf{1})$ was prepared. The differential scanning calorimetry (DSC) measurement shows that $\mathbf{1}$ has three reversible structural phase transitions at around 198.4/183.2, 268/248.2, and 312.3/301.5 K, respectively. Accompanying with multi-state dielectric switching responses in the full temperature range, it also presents interesting fluorescence response by the thermal stimulus. More strikingly, its luminescence response includes the decrease of intensity and blue shift of peak under temperature stimulation. Furthermore, the switching mechanism can be ascribed to the movement of organic cations and the distortion of the inorganic framework or the intensity of their atomic movements. In general, this work successfully achieves triple optic-dielectric state responses under thermal stimulation.

\section{EXPERIMENTAL SECTION}

\section{Synthetic procedures}

The crystals of $\left[\left(\mathrm{CH}_{3}\right)_{3} \mathrm{NOH}\right] \mathrm{MnCl}_{3}$ were prepared by slow evaporation of the mixed solution containing trimethylamine $\mathrm{N}$-oxide dihydrate, hydrochloric acid, and manganese chloride in equal molar ratios. Crystal- lographic data and structure refinement details showed homogeneous and uniform morphology.

\section{Characterizations}

Single-crystal X-ray diffraction (XRD) data were acquired by using a Rigaku Oxford diffractometer equipped with Mo-Ka radiation $(\lambda=0.71073 \AA)$. The structures were solved by direct methods and successive Fourier synthesis and then refined by the full-matrix least-squares method based on $F_{2}$ utilizing the SHELXLTL software package. All non-hydrogen atoms were refined anisotropically and added geometrically. Moreover, the molecular units and the packing views were drawn using DIAMOND (Brandenburg and Putz, 2005). DSC was measured on a PerkinElmer Diamond DSC instrument in the temperature range of $165-330 \mathrm{~K}$ with a heating or cooling rate of $20 \mathrm{~K} \mathrm{~min}^{-1}$ under a nitrogen atmosphere. Complex dielectric constants were measured with a Tonghui TH2828A instrument in the range of $165-330 \mathrm{~K}$. Moreover, ultraviolet-visible (UV-vis) diffuse reflectance spectroscopy measurements were performed by using a Shimadzu (Tokyo, Japan) UV-2600 spectrophotometer with an ISR-2600Plus integrating sphere operating from 200 to $1000 \mathrm{~nm}$ at room temperature. $\mathrm{BaSO}_{4}$ was used as the $100 \%$ reflectance reference.

\section{RESULTS AND DISCUSSION}

Compound $\mathbf{1}$ was prepared in a mixed solution including acetonitrile and methanol, as orange-red rod-like crystals. In the single-crystal XRD study of $\mathbf{1}$ at $300 \mathrm{~K}$ (room temperature), it crystallized in an orthogonal space group Pbcm, with $a=9.2187 \AA, b=15.1758 \AA$, and $c=6.4710 \AA$. Linear $\left[\mathrm{MnCl}_{3}\right]_{n}{ }^{-}$chains of the face-sharing $\mathrm{MnCl}_{6}$ octahedra constructed the framework of the crystal lattice, and the organic cations $\left[\left(\mathrm{CH}_{3}\right)_{3} \mathrm{NOH}\right]^{+}$(named as TMNO) were embedded into the free space between the chains. The structural features formed the typical perovskite structure- $\mathrm{ABX}_{3}$, similar to $\mathrm{BaNiO}_{3}$. Moreover, it could remain stable until $560 \mathrm{~K}$, which was verified by thermogravimetric analysis (TGA) (Fig. S1). The functional groups of organic cation TMNO and the purity of the material were proved by the infrared spectrum and powder XRD (PXRD) spectrum respectively (Figs S2 and S3).

As a direct physical method to reveal the solid-to-solid (STS) phase transitions, the structural phase transitions of compound 1 were verified by DSC firstly (Fig. 1a). During the heating and cooling cycles in the temperature range of $165-330 \mathrm{~K}$, we noted that the material exhibited three pairs of exo- and endo-thermal peaks at around 

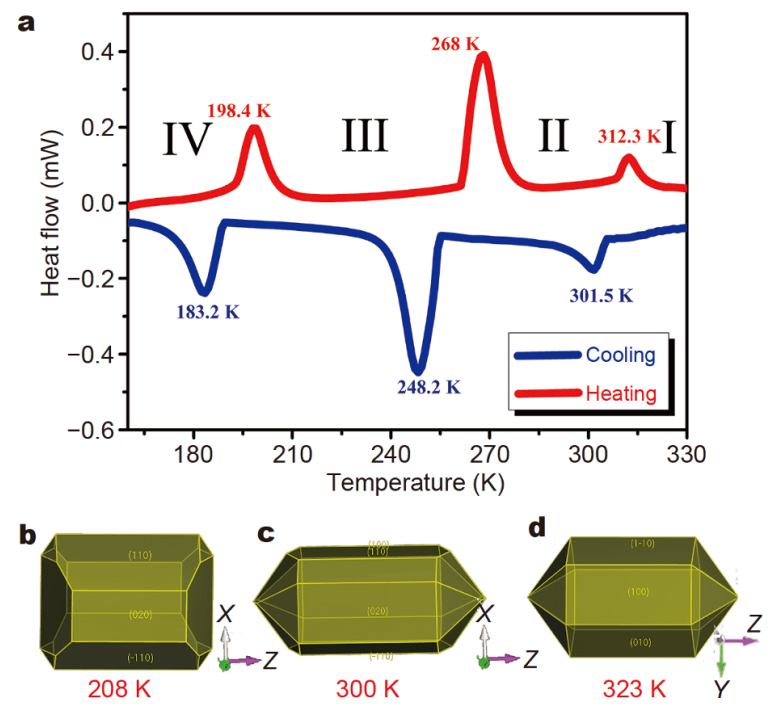

Figure 1 (a) Thermal characterization (DSC plots) of the structural phase transitions in $\mathbf{1}$. The simulative single crystal shape of $\mathbf{1}$ for: $208 \mathrm{~K}$ (b); $300 \mathrm{~K}(\mathrm{c})$; and $323 \mathrm{~K}$ (d).

198.4/183.2 $\left(T_{1 \mathrm{a}}\right), 268 / 248.2\left(T_{1 \mathrm{~b}}\right)$, and $312.3 / 301.5 \mathrm{~K}$ $\left(T_{1 c}\right)$, respectively. The average entropy changes $\Delta S$ of phase transitions corresponding to compound 1 were calculated as $5.66,8.94$, and $1.10 \mathrm{~J} \mathrm{~mol}^{-1} \mathrm{~K}^{-1}$, respectively. Conveniently, we divided the whole process into four parts according to the phase transition temperature, as Phases I-IV. Further exploring the microscopic mechanism of the STS phase transitions, we obtained the structures of 1 at different phase states by using singlecrystal XRD. These four phases are represented by structures at $323,300,208$, and $153 \mathrm{~K}$, respectively. However, we only obtained crystal structures and simulated crystals at 208, 300, and $323 \mathrm{~K}$. As Fig. $1 \mathrm{~b}-\mathrm{d}$ show, the changes of their crystal planes indicate the phase transitions. As for $153 \mathrm{~K}$ (Phase IV), due to poor crystal data collection, we could not obtain the specific crystal structure and its simulated crystal. Fortunately, we obtained the cell parameters at different temperatures. The angle value of $\beta$ changed distinctly from $90^{\circ}$ for Phase III to $93^{\circ}$ for Phase IV (Fig. 2a). Moreover, variable-temperature PXRD measurements were performed to prove their phase transitions. As depicted in Fig. 2b, the PXRD patterns recorded at 148 and $168 \mathrm{~K}$ match quite well; however, as the temperature increased, the diffraction at $2 \theta=16.17^{\circ}, 22.07^{\circ}$, and $26.52^{\circ}$ appeared as clear peaks, and the diffraction peak at $2 \theta=37.63^{\circ}$ gradually disappeared from Phase IV to Phase III. Based on the above analysis, the evident variations of the PXRD patterns at around $T_{1 \mathrm{a}}$ verified the occurrence of the structural phase transition.

Other phases were compared with the specific crystal data (Table S1), packing structures (Figs 3 and 4), and molecular structures (Fig. 5) to discuss their differences and similarities. At $208 \mathrm{~K}$ of Phase III, it crystallized in space group Pmcn, which also belongs to the orthorhombic crystal system with $a=9.6079 \AA, b=14.2701 \AA$, and $c=6.4163 \AA$. As shown in Fig. 3a, linear $\left[\mathrm{MnCl}_{3}\right]_{n}{ }^{-}$ chains (along the $c$ axis) of face-sharing $\mathrm{MnCl}_{6}$ octahedra construct the framework of the crystal lattice, of which the $\mathrm{Mn}$ atoms and one-third of the $\mathrm{Cl}$ atoms lie in the mirror plane, while the other $\mathrm{Cl}$ atoms do not. This mirror also passes through the oxygen atoms of TMNO cations, as shown in the sky blue area of Fig. 3a. When the temperature rises to $300 \mathrm{~K}$ of Phase II, all the $\mathrm{Mn}-\mathrm{Cl}$ bond lengths and $\mathrm{Cl}-\mathrm{Mn}-\mathrm{Cl}$ bond angles are changed within the normal ranges (Table S2). It is worth noting that the dynamics of their organic cations change from relatively stationary motions to tumbling motions, causing the phase transition. As shown in Fig. $3 \mathrm{~b}$, all $\mathrm{Cl}$ atoms are in the mirror plane, while $\mathrm{Cd}$ atoms are not. The tumbling motions of TMNO cations are symmetrical in
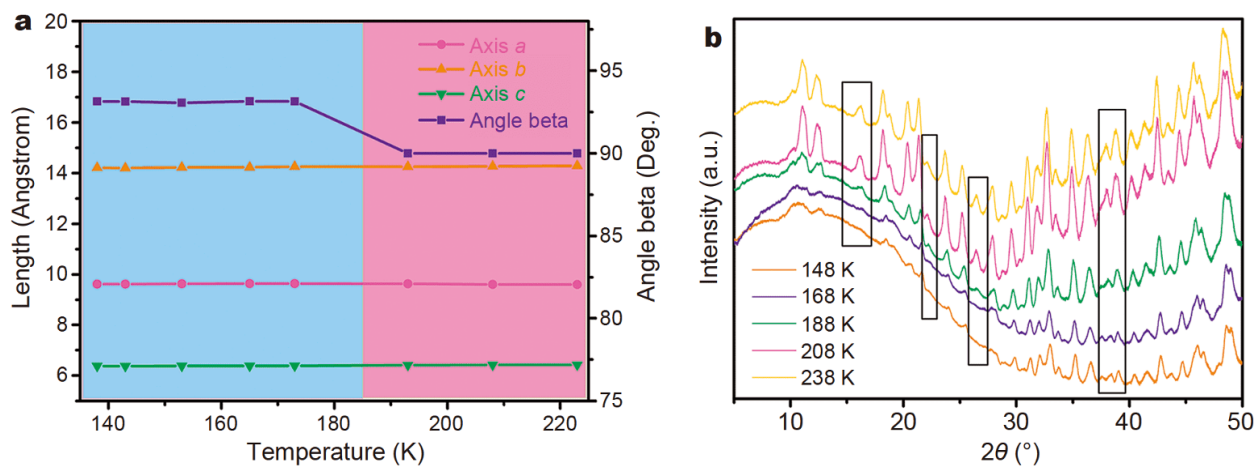

Figure 2 (a) Changing of cell parameters $a, b, c$, and $\beta$ value at different temperatures. (b) PXRD patterns of $\left[\left(\mathrm{CH}_{3}\right)_{3} \mathrm{NOH}\right]\left[\mathrm{MnCl}_{3}\right]$ at different temperatures. 


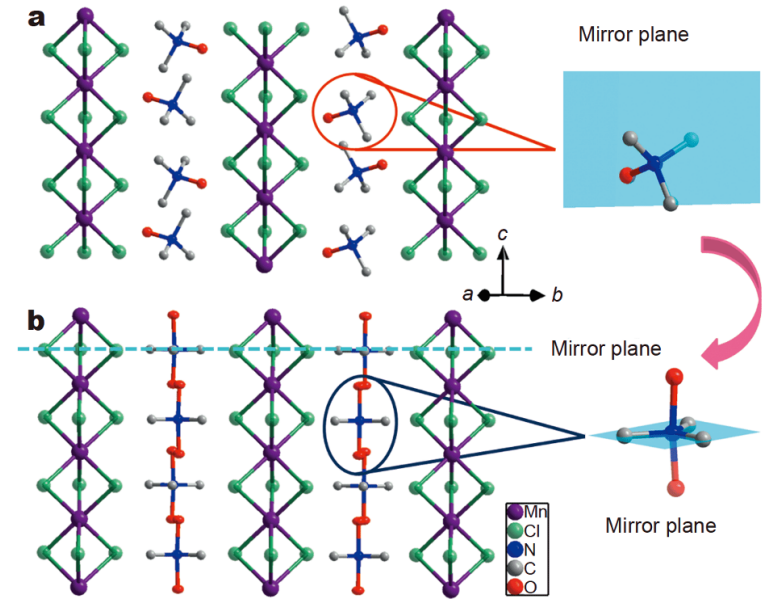

Figure 3 Packing views of 1 in: (a) Phase III (208 K); and (b) Phase II $(300 \mathrm{~K})$. The sky blue plane represents the mirror plane. The $\mathrm{H}$ atoms of the cations were omitted for clarity.

the mirror plane, and all $\mathrm{C}$ atoms lie in the mirror plane too. These differences can be attributed to the change of symmetry elements. In general, the overall unit cell frameworks at 208 and $300 \mathrm{~K}$ have almost no differences (Fig. 3). The main reason for the phase transition (Phase III to Phase II) is the movement of organic cations (Fig. 5a, b).

To reveal the mechanism of phase transition above room temperature, we compared the crystal structures at 300 and $323 \mathrm{~K}$. Compound 1 of Phase I at $323 \mathrm{~K}$ belongs to the hexagonal centrosymmetric space group $\mathrm{P6}_{3} / \mathrm{mmc}$. The spatial symmetry operations change from eight
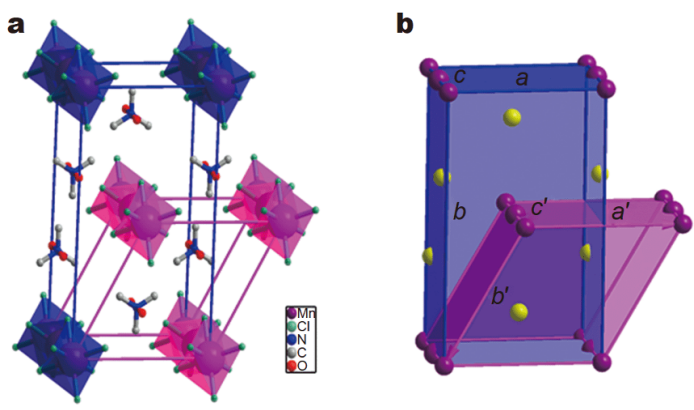

Figure 4 (a) The crystal cell of 1 in Phase II (outlined in blue solid lines) and its unit cell in Phase I (outlined in black solid lines). (b) Schematic diagram of the lattice of 1 from Phase II to Phase I.

elements $\left(E, C_{2}, C_{2}{ }^{\prime}, C_{2}{ }^{\prime \prime}, i, \sigma_{\mathrm{h}}, \sigma_{\mathrm{v}}\right.$, and $\left.\sigma_{\mathrm{v}}{ }^{\prime}\right)$ in Phase II to the twenty-four symmetry elements $\left(E, 2 C_{6}, 2 C_{3}, C_{2}, 3 C_{2}^{\prime}\right.$, $3 C_{2}^{\prime \prime}, i, 2 S_{3}, 2 S_{6}, \sigma_{\mathrm{h}}, 3 \sigma_{\mathrm{v}}$, and $3 \sigma_{\mathrm{d}}$ ) in Phase I (Fig. S4). Each $\mathrm{Mn}$ atom, lying in the $3 \mathrm{~m}$ symmetry site, is octahedrally coordinated with six bridging $\mathrm{Cl}$ atoms with $\mathrm{Mn}-\mathrm{Cl}$ bond length changing to 2.538 (2) $\AA$ and the $\mathrm{Cl}-\mathrm{Mn}-\mathrm{Cl}$ bond angles ranging from 83.93(6)-96.07(6) ${ }^{\circ}$ to $180.00(4)^{\circ}$ (Table S2). During the heating process, 1D chains remains running along the $c$ axis, but the structural parameters change tremendously $[a, b, c(\AA): 9.6079$ (19), 14.2701(3), and 6.4163(14) vs. 8.9670(7), 8.9670(7), and 6.4506(5); $V\left(\AA^{3}\right)$ : 945.5(3) vs. 449.18(9)]. The unit cells of these two phases are shown in Fig. 4. Thermal vibrations of the atoms become more intense at a high temperature (Phase I), especially for $\mathrm{N}, \mathrm{C}$, and $\mathrm{O}$ atoms (Fig. 5b, c).

Based on the above analysis, to understand the changes

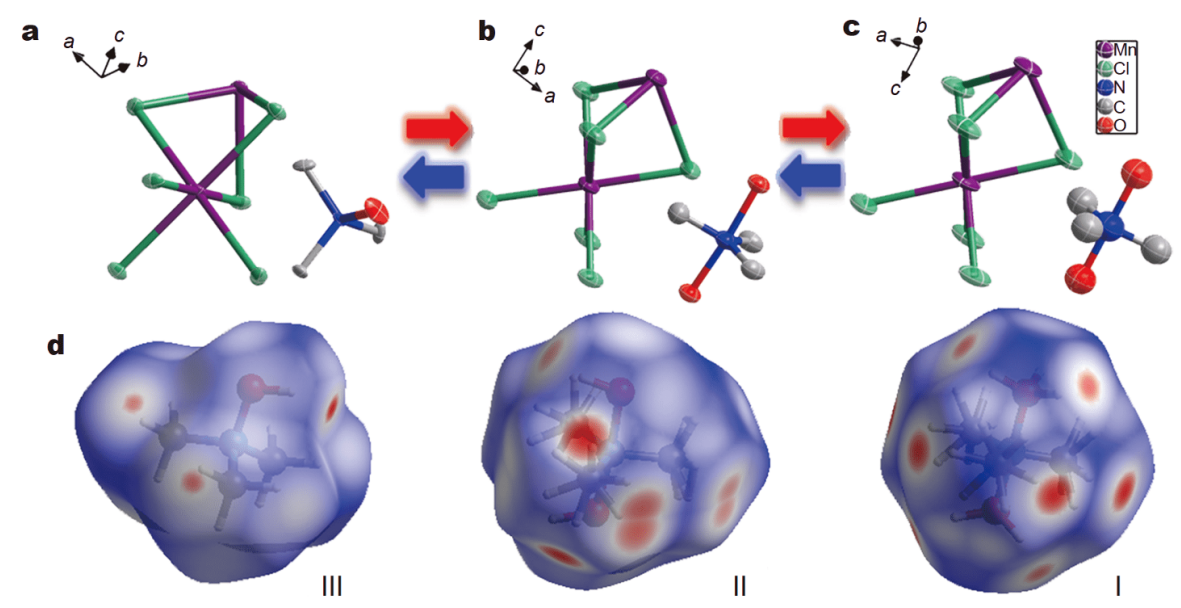

Figure 5 Crystal structures of $\mathbf{1}$ with thermal ellipsoids drawn at 30\% probability for the inorganic part and $10 \%$ for the organic part, with hydrogen atoms omitted for clarity: (a) $208 \mathrm{~K}$ for Phase III; (b) $300 \mathrm{~K}$ for Phase II; and (3) $323 \mathrm{~K}$ for Phase I. Comparison between the Hirshfeld $d_{\text {norm }}$ surfaces of different phases (d). On Hirshfeld surfaces, the red, white, and blue regions represent molecular contacts shorter than, equal to, and longer than the van der Waals distance, respectively. 
in the interaction between TMNO cations and $\left[\mathrm{MnCl}_{3}\right]_{n}^{-}$ chains, Hirshfeld surface analysis was performed. As shown in Fig. 5d, the red spots on their Hirshfeld surfaces become larger from phases III to I, indicating that the interaction between TMNO cations and $\left[\mathrm{MnCl}_{3}\right]_{n}{ }^{-}$chains gradually increases. It is probably caused by the more intense movement of TMNO cations in a limited space, corresponding to crystal structure analysis.

Generally, the solid phase transitions can bring dielectric anomalies. Here, we measured the temperaturedependent dielectric constant of 1 . Fig. 6a, b show the temperature-dependent real part $\left(\varepsilon^{\prime}\right)$ of the permittivity in the ranges of $165-280 \mathrm{~K}$ and $280-330 \mathrm{~K}$, respectively.
Three distinct dielectric anomalies were scattered among the range, consistent with the DSC results. Upon heating, at $1000 \mathrm{kHz}$, the value of the real part $\varepsilon^{\prime}$ started at about 4 at $165 \mathrm{~K}$ and then increased slowly with the temperature increasing in the Phase IV state. At $201 \mathrm{~K}$ (around $T_{1 \mathrm{a}}$ ), the value of $\varepsilon^{\prime}$ presented the anomalies. Above $T_{1 \mathrm{a}}$, compound $\mathbf{1}$ is in the Phase III state and the $\varepsilon^{\prime}$ values increase more slowly than in Phase IV with the temperature increasing. At around $261 \mathrm{~K}\left(T_{1 \mathrm{~b}}\right)$, the real part $\left(\varepsilon^{\prime}\right)$ of $\mathbf{1}$ remained at approximately 5.5 , afterward, an inverted peak appeared. The dielectric anomalies were $\mathrm{Z}$ shaped, corresponding to the second phase transition (Phase III to Phase II). As the temperature continued to
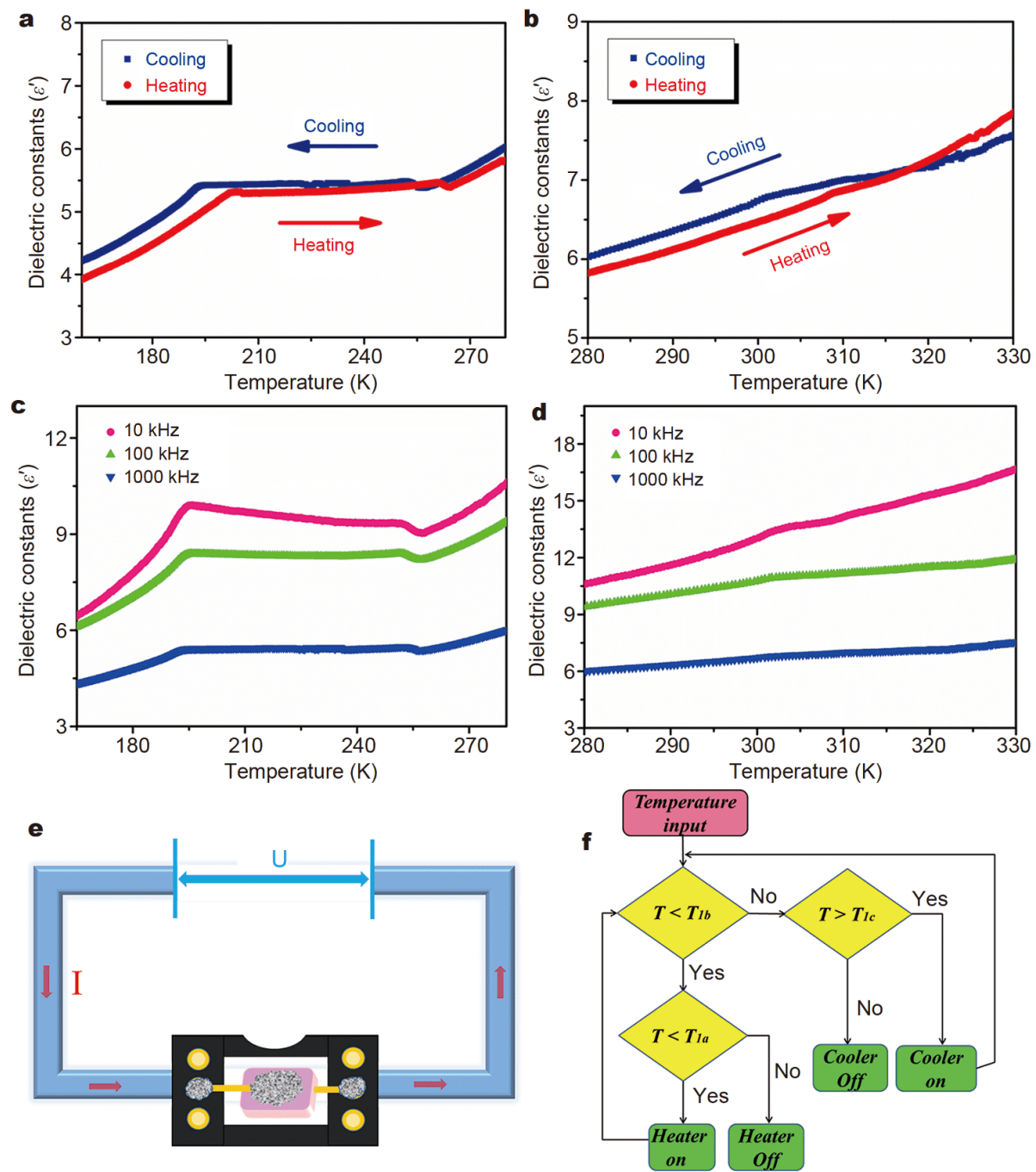

Figure 6 (a) Temperature-dependent real part dielectric constant of 1 at $1000 \mathrm{kHz}$ upon heating and cooling below room temperature. (b) Temperature-dependent real part dielectric constant of 1 at $1000 \mathrm{kHz}$ upon heating and cooling above room temperature. (c) Temperature-dependent real part dielectric constant of $\mathbf{1}$ cooling below room temperature. (d) Temperature-dependent real part dielectric constant of $\mathbf{1}$ cooling above room temperature. (e) Schematic diagram of dielectric measurements for powder-pressed pellets. (f) Logic diagram in temperature-controlled device. 
rise above room temperature, the real part $\left(\varepsilon^{\prime}\right)$ was still rising (from Phase II to Phase I), accompanied by the third dielectric anomaly in the vicinity of $312 \mathrm{~K}$, which supports the existence of the phase transition. As for the cooling process, similar dielectric anomalies appeared, confirming the reversibility of the phase transitions. In addition, we display the temperature-dependent dielectric of selected frequencies 10-1000 kHz. As shown in Fig. 6c, $\mathrm{d}$, the dielectric anomalies at different frequencies of $\mathbf{1}$ keep similar behaviors. Overall, these results confirm that $\mathbf{1}$ can be regarded as a temperature-responsive dielectric material. The details of the dielectric measurement mechanism schematic are illustrated in Fig. 6e. The logic diagram in Fig. $6 f$ shows the temperature-control process in the imaginary system. When the temperature was above $T_{1 \mathrm{~b}}$, it entered the cooling system; above $T_{1 \mathrm{c}}$, the cooler was on, while below it was off. On the contrary, when the temperature was below $T_{1 b}$, it entered the heating system; above $T_{1 \mathrm{a}}$, the heater was off, while below it was on. This could also give feedback to the temperature system.

Besides the switching dielectric response under the thermal stimulus, 1 also shows intriguing luminescence properties. As shown in Fig. 7a and b, the crystals (put into quartz cuvettes and formed into the shape of "TSRM") were orange-red and somewhat transparent under ambient light. When illuminated with a UV lamp, they showed a strong red light (Fig. 7c, d). Fig. 7e presents the three strong absorption peaks that were observed for the absorption spectrum of $\mathbf{1}$. The first one is in the UV band at around $375 \mathrm{~nm}$, and the other two are in the visible region centered at around 445 and $535 \mathrm{~nm}$ respectively. Then, upon excitation at around 375, 450, and $540 \mathrm{~nm}$, the emission spectra of compound 1 exhibited broad emission at around $640 \mathrm{~nm}$ (the full width at half maximum (FWHM) is approximately $86 \mathrm{~nm}$ ) (Fig. 7f). The red fluorescence at around $640 \mathrm{~nm}$ is produced by octahedrally coordinated manganese, which is attributable to the $\left(\mathrm{t}_{2 \mathrm{~g}}\right)^{3}\left(\mathrm{e}_{\mathrm{g}}\right)^{2}-\left(\mathrm{t}_{2 \mathrm{~g}}\right)^{4}\left(\mathrm{e}_{\mathrm{g}}\right)^{1}$ electronic transition [34]. By using the strong fluorescence emission wavelength $(640 \mathrm{~nm})$, the photoluminescence excitation (PLE) spectrum was recorded, as shown in Fig. 7e. Obviously, the PLE spectra and UV-vis absorption spectra had similar peak positions.

Further exploring the thermo-responsiveness of their luminescent properties, we studied the fluorescence properties of the material (powder samples) at different temperatures. As shown in Fig. 8a, upon increasing the temperature from 153 to $323 \mathrm{~K}$, the emission intensity of 1 significantly decreases. According to the numerical
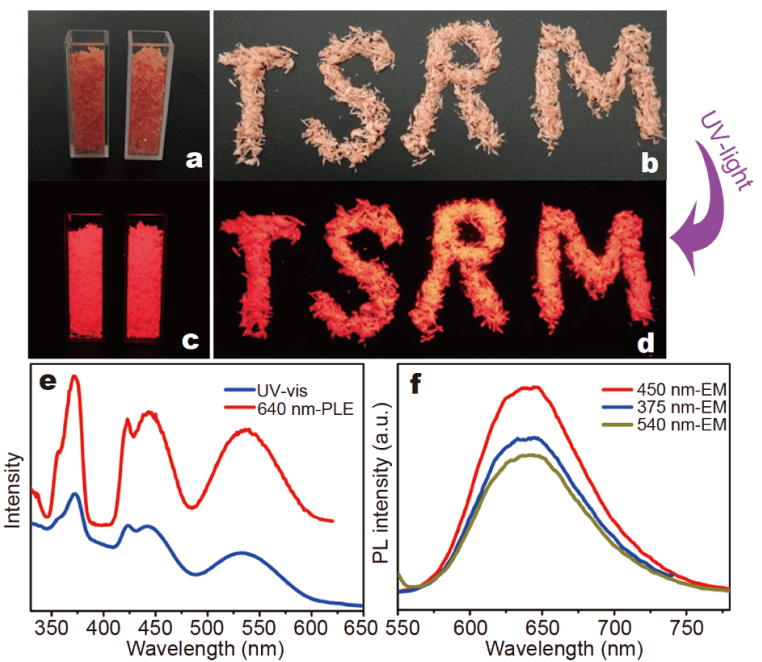

Figure 7 Photoluminescence properties of compound 1. The orangered crystal of compound $\mathbf{1}$ was put into two quartz cuvettes under natural light (a) and emitted strong red light under UV light in the darkroom (b). The shape of "TSRM" formed by crystal samples of $\mathbf{1}$ under natural light (c) and UV light (d). (e) UV-vis absorption spectra and PLE spectrum. (f) Emission spectra at various excitation wavelengths.

calculation of the highest emission peak, the emission intensity dropped by $25 \%$ over this temperature range. This phenomenon can be attributed to intense molecular motions as the temperature increasing, improving the rate of on-radiative transition. Besides, the emission maximum gradually shifted from 660 to $635 \mathrm{~nm}$ in the temperature range. Especially, from 238 to $265 \mathrm{~K}$, the peak shape and position of the emission maximum changed relatively significantly (Fig. 8b).

\section{CONCLUSIONS}

By rational design and chemical synthesis, we obtained a new thermal stimuli-responsive material, $\left[\left(\mathrm{CH}_{3}\right)_{3} \mathrm{NOH}\right]$ $\left[\mathrm{MnCl}_{3}\right]$, with switchable dielectric and luminescence responses. In the low, room, and high temperatures, three dielectric anomaly signals are distributed. It also shows noticeable stimulating responses about the intensity and peak position of fluorescence. More strikingly, the decrease rate in fluorescence intensity is fastest from Phase III to Phase II and the blue shift rate of fluorescence maximum absorption peak is also the fastest within the entire temperature range. Through the crystal structure analysis at different temperatures, these responses can be ascribed to the motions or reorientations of $\left[\left(\mathrm{CH}_{3}\right)_{3} \mathrm{NOH}\right]^{+}$cations and the weak distortion of the inorganic framework. The lead-free hybrid perovskite with triple optic-dielectric states has great significance for 

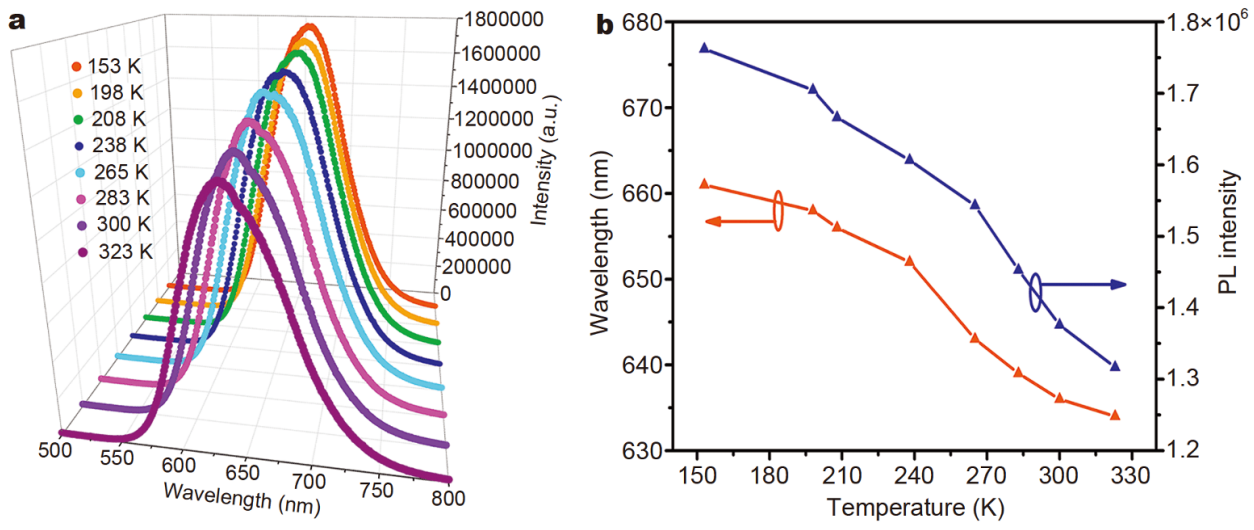

Figure 8 (a) Temperature-responsive emission properties of crystal 1 between 153 and $323 \mathrm{~K}$. (b) The blue line represents the peak value changes of luminescent intensity from crystal $\mathbf{1}$ in the heating process and the red line represents the peak wavelength position changes of luminescent from crystal 1 in the heating process.

developing full-temperature covered switching material. Therefore, the method, introducing the self-assembly of organic and inorganic components, provides ideas for designing multi-responsive thermal stimulating materials.

\section{Received 6 March 2020; accepted 1 April 2020; published online 24 June 2020}

1 Jaffe A, Lin Y, Mao WL, et al. Pressure-induced conductivity and yellow-to-black piezochromism in a layered $\mathrm{Cu}-\mathrm{Cl}$ hybrid perovskite. J Am Chem Soc, 2015, 137: 1673-1678

2 Náfrádi B, Szirmai P, Spina M, et al. Optically switched magnetism in photovoltaic perovskite $\mathrm{CH}_{3} \mathrm{NH}_{3}(\mathrm{Mn}: \mathrm{Pb}) \mathrm{I}_{3}$. Nat Commun, 2016, 7: 13406

3 Shi Y, Wang J, Li H, et al. A simple multi-responsive system based on aldehyde functionalized amino-boranes. Chem Sci, 2018, 9: 1902-1911

4 Wu C, Dai J, Zhang $\mathrm{X}$, et al. Synthetic Haggite $\mathrm{V}_{4} \mathrm{O}_{6}(\mathrm{OH})_{4}$ nanobelts: Oxyhydroxide as a new catalog of smart electrical switch materials. J Am Chem Soc, 2009, 131: 7218-7219

5 Ren L, Sun S, Casillas-Garcia G, et al. A liquid-metal-based magnetoactive slurry for stimuli-responsive mechanically adaptive electrodes. Adv Mater, 2018, 30: 1802595

6 Döbbelin M, Tena-Zaera R, Marcilla R, et al. Multiresponsive PEDOT-ionic liquid materials for the design of surfaces with switchable wettability. Adv Funct Mater, 2009, 19: 3326-3333

7 Kahn O. Spin-transition polymers: from molecular materials toward memory devices. Science, 1998, 279: 44-48

8 Yao L, Xu P, Gao WR, et al. A chain-type diamine strategy towards strongly anisotropic triiodide of DMEDA.I6. Sci China Mater, 2020, 63: 566-574

9 Chen SL, Yang ZR, Wang BJ, et al. Molecular perovskite highenergetic materials. Sci China Mater, 2018, 61: 1123-1128

10 Zhang W, Cai Y, Xiong RG, et al. Exceptional dielectric phase transitions in a perovskite-type cage compound. Angew Chem Int Ed, 2010, 49: 6608-6610

11 Shi C, Han XB, Zhang W. Structural phase transition-associated dielectric transition and ferroelectricity in coordination compounds. Coord Chem Rev, 2019, 378: 561-576
12 Zhang Q, Wang W, Zhang J, et al. Thermally induced bending of $\mathrm{ReS}_{2}$ nanowalls. Adv Mater, 2018, 30: 1704585

13 Feng J, Tian $\mathrm{K}, \mathrm{Hu} \mathrm{D}$, et al. A triarylboron-based fluorescent thermometer: sensitive over a wide temperature range. Angew Chem Int Ed, 2011, 50: 8072-8076

14 Shi PP, Ye Q, Li Q, et al. Novel phase-transition materials coupled with switchable dielectric, magnetic, and optical properties: $\left[\left(\mathrm{CH}_{3}\right)_{4} \mathrm{P}\right]\left[\mathrm{FeCl}_{4}\right]$ and $\left[\left(\mathrm{CH}_{3}\right)_{4} \mathrm{P}\right]\left[\mathrm{FeBr}_{4}\right]$. Chem Mater, 2014, 26: 6042-6049

15 Stuart MAC, Huck WTS, Genzer J, et al. Emerging applications of stimuli-responsive polymer materials. Nat Mater, 2010, 9: 101-113

16 Kim Y, Yuk H, Zhao R, et al. Printing ferromagnetic domains for untethered fast-transforming soft materials. Nature, 2018, 558: 274-279

17 Saparov B, Mitzi DB. Organic-inorganic perovskites: Structural versatility for functional materials design. Chem Rev, 2016, 116: 4558-4596

18 Chu L, Ahmad W, Liu W, et al. Lead-free halide double perovskite materials: A new superstar toward green and stable optoelectronic applications. Nano-Micro Lett, 2019, 11: 16

19 Shi C, Yu H, Wang QW, et al. Hybrid organic-inorganic antiperovskites. Angew Chem Int Ed, 2020, 59: 167-171

20 Zhou L, Zheng X, Shi PP, et al. Switchable nonlinear optical and tunable luminescent properties triggered by multiple phase transitions in a perovskite-like compound. Inorg Chem, 2017, 56: 3238-3244

21 Wang Z, Zhang Z, Tao L, et al. Hybrid chloroantimonates(III): thermally induced triple-mode reversible luminescent switching and laser-printable rewritable luminescent paper. Angew Chem Int Ed, 2019, 58: 9974-9978

22 Li L, Jin L, Zhou Y, et al. Filterless polarization-sensitive 2D perovskite narrowband photodetectors. Adv Opt Mater, 2019, 7: 1900988

23 Wang BY, He CT, Huang B, et al. Thermal-induced reversible ferroelastic phase transition in a new bromethyl-substituted molecular rotor. Sci China Chem, 2015, 58: 1137-1143

24 Shang R, Wang ZM, Gao S. A 36-fold multiple unit cell and switchable anisotropic dielectric responses in an ammonium magnesium formate framework. Angew Chem Int Ed, 2015, 54: 2534-2537 
Ai Y, Chen XG, Shi PP, et al. Fluorine substitution induced high $T_{\mathrm{c}}$ of enantiomeric perovskite ferroelectrics: $(R)$ - and $(S)$-3-(fluoropyrrolidinium) $\mathrm{MnCl}_{3}$. J Am Chem Soc, 2019, 141: 4474-4479

Tang YY, Wang ZX, Li PF, et al. Brilliant triboluminescence in a potential organic-inorganic hybrid ferroelectric: $\left(\mathrm{Ph}_{3} \mathrm{PO}\right)_{2} \mathrm{MnBr}_{2}$. Inorg Chem Front, 2017, 4: 154-159

27 You YM, Liao WQ, Zhao D, et al. An organic-inorganic perovskite ferroelectric with large piezoelectric response. Science, 2017, 357: 306-309

28 Zhang Y, Liao WQ, Fu DW, et al. Highly efficient red-light emission in an organic-inorganic hybrid ferroelectric: (Pyrrolidinium) $\mathrm{MnCl}_{3}$. J Am Chem Soc, 2015, 137: 4928-4931

29 Zhang Y, Liao WQ, Fu DW, et al. The first organic-inorganic hybrid luminescent multiferroic: (Pyrrolidinium) $\mathrm{MnBr}_{3}$. Adv Mater, 2015, 27: 3942-3946

30 Bhaskaran A, Raghavan CM, MohanKumar R, et al. Studies on the structural, optical, dielectric and mechanical properties of nonlinear optical manganese mercury tetrathiocyanate glycol mono methyl ether (MMTG) single crystal. Curr Appl Phys, 2010, 10: 1261-1266

31 Peng Y, Li L, Ji C, et al. Tailored synthesis of an unprecedented $\mathrm{Pb}-\mathrm{Mn}$ Heterometallic halide hybrid with enhanced emission. J Am Chem Soc, 2019, 141: 12197-12201

32 Guo Q, Zhang WY, Chen C, et al. Red-light emission and dielectric reversible duple opto-electronic switches in a hybrid multifunctional material: (2-methylimidazolium) $\mathrm{MnCl}_{3}\left(\mathrm{H}_{2} \mathrm{O}\right)$. J Mater Chem C, 2017, 5: 5458-5464

33 Zhang T, Chen C, Zhang WY, et al. Heat-sensitive structural phase transitions of hybrid halide perovskite with double dielectric ON/ OFF switches. Inorg Chem Front, 2018, 5: 2340-2345

34 Lawson KE. Optical studies of electronic transitions in hexa- and tetracoordinated $\mathrm{Mn}^{2+}$ crystals. J Chem Phys, 1967, 47: 3627-3633

Acknowledgements This work was financially supported by the National Natural Science Foundation of China (21991141), the Natural Science Foundation of Zhejiang Province (LZ20B010001), and Zhejiang Normal University.

Author contributions Zhang $\mathrm{T}$ conceived the experiment, analyzed the data and wrote the paper. Zhang $\mathrm{Z}$ and $\mathrm{Li} \mathrm{J}$ conducted the material characterizations and data analyses. Chu $\mathrm{L}$ conducted the material synthesis. Zhang $\mathrm{W}$ and Shi P provided suggestions to the final version of the manuscript. Fu DW and Ye Q guided and supervised this work. All authors contributed to the manuscript.

Conflict of interest The authors declare that they have no conflict of interest.

Supplementary information online version of the paper.

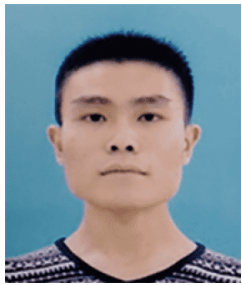

Tie Zhang is a $\mathrm{PhD}$ candidate in the group of Prof. Da-Wei Fu at the Ordered Matter Science Research Center, Jiangsu Key Laboratory for Science and Applications of Molecular Ferroelectrics, Southeast University, Nanjing. His research interest focuses on the molecular perovskite material design with stimulus-response.

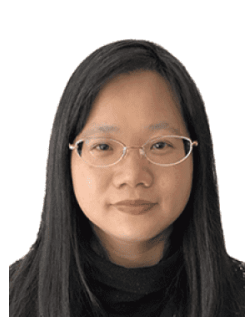

Qiong Ye was born in January 1982. She earned her $\mathrm{PhD}$ in 2007 from Nanjing University and then held a postdoctoral fellowship of Japan Society for the Promotion of Science (JSPS) in Japan over the next two years. Now she is a professor of Jiangsu Key Laboratory for Science and Applications of Molecular Ferroelectrics in Southeast University, with the main research interests in dielectric, ferroelectric, and ferroelastic materials.

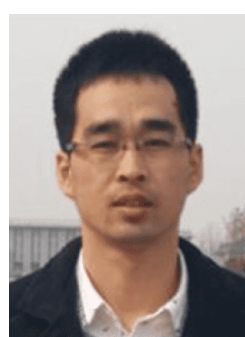

Dawei Fu was born in November 1980. He received his $\mathrm{PhD}$ degree from Southeast University in 2012. Since 2013, he has been a professor and doctoral tutor at Southeast University. His current research interest includes designing highperformance molecular dielectric/ferroelectric materials and ferroelectric electroluminescent devices.

\section{全温度覆盖的三重介电及苂光响应无铅杂化钻钛 矿开关材料}

张铁 ${ }^{1,2}$, 储璐璐 ${ }^{1}$, 张志旭 ${ }^{1}$, 李杰 ${ }^{1}$, 张婉莹 ${ }^{2}$, 石萍萍 ${ }^{1}$, 叶琼 ${ }^{{ }^{*}}$, 付大伟 ${ }^{1,2^{*}}$

摘要 光电响应材料在温度传感、执行器、存储和功能开关领域 的应用引起了广泛关注. 然而将各种功能整合形成多功能响应材 料仍具有挑战性. 分子基杂化材料通常是有机和无机成分的杂化 混合体. 因此, 可以通过结构构建将多个功能复合在一个材料中. 虽然器件应用需要全温度覆盖, 迄今为止却很少能成功地合成全 温度覆盖的多开关响应杂化材料. 在本文中, 动态 $\left[\left(\mathrm{CH}_{3}\right)_{3} \mathrm{NOH}\right]^{+}$阳 离子和发光中心 $\mathrm{Mn}(\mathrm{II})$ 形成杂化材料 $\left[\left(\mathrm{CH}_{3}\right)_{3} \mathrm{NOH}\right]\left[\mathrm{MnCl}_{3}\right]$, 该材 料在温度刺激下显示出多重响应行为. 温度变化时, $\left[\left(\mathrm{CH}_{3}\right)_{3} \mathrm{NOH}\right]-$ $\left[\mathrm{MnCl}_{3}\right]$ 在全温度范围(低温、室温和高温)下表现出多重介电态及 发光强度或峰值变化的开关响应. 这些响应行为是由 $\left[\left(\mathrm{CH}_{3}\right)_{3}\right.$ $\mathrm{NOH}]^{+}$阳离子和无机骨架的运动或重新取向而触发的. 总之, 这种 光电开关材料在多重加密存储和传感设备中具有潜在的应用. 